\section{Physical Compatibility of Ranitidine and Metoclopramide in 50-mL Minibags of Normal Saline}

Ranitidine and metoclopramide are routinely given intravenously before surgical procedures that involve spinal or general anesthesia. Recently, another institution contacted our institution to request stability data to support the practice of routinely mixing ranitidine $50 \mathrm{mg}$ and metoclopramide $10 \mathrm{mg}$ in a $50-\mathrm{mL}$ minibag of normal saline $(0.9 \%$ sodium chloride) for IV administration before cesarean section. Before receiving this request, we had been unaware of this practice and assumed that these medications were to be administered either concurrently via the Y-site connector or consecutively. However, when questioned about the administration of these 2 medications, the nursing staff unanimously reported that this practice had been followed for more than 5 years on our institution's maternity ward, as well as in the adult surgical daycare unit. The authors contacted other large maternity centres in the region and discovered only one other site that was mixing ranitidine and metoclopramide before administration.

Commonly used compatibility references, including Trissel's handbook ${ }^{1}$ and the King Guide, ${ }^{2}$ were reviewed, a literature search was performed, and site-specific policies were reviewed for information about the specific combination of ranitidine $50 \mathrm{mg}$ and metoclopramide $10 \mathrm{mg}$ in $50 \mathrm{~mL}$ of normal saline; however, no stability or compatibility data were found. Ranitidine and metoclopramide are reported to be physically compatible at the Y-site connector and when combined in a syringe (without normal saline). ${ }^{1,2}$ In addition, in a study first published in 2010, Cabrera and others ${ }^{3}$ evaluated the chemical and physical compatibility of an admixture containing 4 medications (ranitidine $150 \mathrm{mg}$, metoclopramide $50 \mathrm{mg}$, tramadol $500 \mathrm{mg}$, and ketorolac $150 \mathrm{mg}$ in normal saline) stored at room temperature for $48 \mathrm{~h}$, because this admixture was to be infused over $48 \mathrm{~h}$ for pain control. The authors found no change in colour, formation of precipitate, or phase separation. When the mean concentration of each drug was tested at $48 \mathrm{~h}$, metoclopramide remained between $100 \%$ and $105 \%$ of its initial level and ranitidine between $99 \%$ and $102 \%$ of its initial level.

We conducted a small physical compatibility study by preparing a bag of ranitidine $50 \mathrm{mg}(25 \mathrm{mg} / \mathrm{mL}$; GlaxoSmith Kline, lot C618668, expiry August 2014) and metoclopramide $10 \mathrm{mg}(10 \mathrm{mg} / 2 \mathrm{~mL}$; Sandoz, lot CX8994, expiry October 2015 ) in $50 \mathrm{~mL}$ of normal saline (Baxter, lot W3E07C0, expiry May 2014). This admixture was left at room temperature (about $25^{\circ} \mathrm{C}$ ) for $72 \mathrm{~h}$. The bag was assessed at $1,17,26,41$, and $72 \mathrm{~h}$; at each time point, there was no visible evidence of colour change, precipitate, or phase separation in the admixture. Although these results do not exclude the risk of incompatibility or changes in efficacy, this information does add to the clinical data at our site indicating that these 2 medications are physically compatible when combined in normal saline.

We would be interested to learn about others' experience with this drug combination, including further clinical or laboratory stability data for the administration of ranitidine and metoclopramide in normal saline.

\section{References}

1. Trissel LA. Handbook on injectable drugs. 17th ed. Bethesda (MD): American Society of Health-System Pharmacists; 2013.

2. Patrick CN, editor. King Guide to parenteral admixtures: 2010 critical care Y-site compatibility. Napa (CA): King Guide Publications; 2010.

3. Cabrera J, Mancuso M, Cabrera-Fránquiz F, Limiñana J, Diez A. Stability and compatibility of the mixture of tramadol, ketorolac, metoclopramide and ranitidine in a solution for intravenous perfusion. Farm Hosp. 2011;35(2):80-83.

Hilary Rowe, BSC(Pharm), PharmD, ACPR

Clinical Pharmacy Specialist-Maternal Fetal Medicine

Jennifer Riley, BSCN, RN

Clinical Nurse Educator, Family Birthing Unit

Brandi Newby, BSc(Pharm), ACPR

Clinical Pharmacy Specialist-Neonatal Intensive Care Unit

Surrey Memorial Hospital, Fraser Health Authority

Surrey, British Columbia

Competing interests: None declared. 